\title{
ESCUELA \\ Cinco De Septiembre
}

\section{Reseña sobre el acercamiento a una institución de educación primaria en La Habana, Cuba.}

\section{Plinio A. Gonzalez P**}

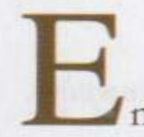

n el marco del evento " Pedagogía 2001 " (Encuentro por la Unidad de los Educadores Latinoamericanos) realizado del 5 al 9 de Febrero de 2001, en el Palacio de Convenciones de La Habana, Cuba, se ofreció la posibilidad de visitar centros docentes de diferentes niveles para intercambiar ideas y experiencias pedagógicas. La Escuela Cinco de Septiembre del municipio de la Lisa, fue una de las seleccionadas.

La Escuela 5 de Septiembre, del municipio de la Lisa, nos empezó a mostrar lo que guarda por dentro cuando sus niñas y niños nos recibieron con estas palabras: "Los niños cubanos somos pioneros y por eso cuidamos respetuosamente nuestros atributos pioneriles. Cada día le rendimos respeto a nuestra bandera y a José Martí. En nuestra escuela, cada día nos esperan tareas y nuevos conocimientos que cumplimos con responsabilidad. Dentro de las escuelas cubanas cada curso es un destacamento que cuenta con tres jefes: un jefe de destacamento, un jefe de tropa y un jefe de actividades; a estos cargos tenemos derecho de acceder tanto las niñas como los niños. Periódicamente se realiza un encuentro juvenil para examinar la vida coti-

\footnotetext{
* Profesor Facultad de Educación Física. Universidad Pedagógica Nacional.
}

diana de la escuela, a dicho encuentro asiste nuestro jefe de destacamento. Todos los pioneros portamos una pañoleta de un color especifico: los estudiantes del primer ciclo llevan una pañoleta azul, que representa el color de nuestro cielo, y los estudiantes del segundo ciclo llevan una pañoleta roja, que representa la sangre derramada en las gestas por nuestra independencia. Viva Cuba Libre".

En Cuba, las escuelas primarias se encargan de la formación elemental general, de primero a sexto grado. Por ser la base de los restantes subsistemas de educación, abarca la mayor población en edad escolar. Entre sus objetivos fundamentales tiene el de contribuir a la formación integral de la personalidad, basada en la estrecha relación que existe entre la educación, la formación y el desarrollo. Comprende 6 grados estructurados en 2 ciclos: 
En el primer ciclo, 1- 4 grados se imparten conocimientos esenciales de las materias instrumentales, Lengua Española y Matemática, encargadas de dotar al escolar de las habilidades indispensables para el aprendizaje. Además, el niño recibe nociones elementales relacionadas con la naturaleza y la sociedad, y realiza actividades de educación física laboral y estética que contribuyen a su formación multilateral.

En el segundo ciclo, 5 - 6 grados continúa el desarrollo de habilidades iniciado en el primero, y el comienzo de nuevas asignaturas: Historia de Cuba, Geografía de Cuba, Ciencias $\mathrm{Na}$ turales y Educación Cívica.

Seguidamente, el coro interpretó canciones y poesias que rinden memoria a la lucha por la independencia. Un banda de guerra, conformada únicamente por instrumentos de percusión, ejecutó una marcha para finalizar el recibimiento.

El Director de la institución expone a los visitantes la organización académico-administrativa de la escuela, de la siguiente manera: "Contamos con 21 maestros licenciados y 10 que estudian licenciatura; además, nos apoyan 21 auxiliares pedagógicas entre las que se cuentan los maestros de Inglés y Educación Fisica, el equipo de logopedas, la bibliotecaria, las enfermeras, la doctora (médico), las nutricionistas y el personal auxiliar de administración. Aunque yo soy el Director, el grupo que dirige las actividades metodológicas y administrativas es el Consejo de Dirección. Con lo anterior se cumple con el objetivo del socialismo, que es formar personas integrales, instruidas, capaces de amar el trabajo, capaces de amar a nuestra patria grande (América Latina), y de servir a la sociedad. Se les enseña a amar a todos los humanos, y a la tierra con todos sus componentes".

El nivel primario presta especial atención al desarrollo de habilidades y capacidades tanto intelectuales como prácticas, a la formación de

\section{En los círculos infantiles y} escuelas primarias, los alumnos asisten a huertos escolares y parcelas productivas, en las que se dedican al cultivo de hortalizas y vegetales de ciclo corto, destinados al autoconsumo de los propios centros docentes.

hábitos de trabajo independiente, a la adquisición de normas de conducta y convivencia social, así como a sentar las bases para la formación de convicciones patrióticas y morales.

En los círculos infantiles y escuelas primarias, los alumnos asisten a huertos escolares y parcelas productivas, en las que se dedican al cultivo de hortalizas y vegetales de ciclo corto, destinados al autoconsumo de los propios centros docentes.

"El aparato de dirección trabaja en la planificación, ejecución, socialización, control y evaluación de las actividades, desde el inicio basta el final del curso; en éste momento, evaluamos a todos nuestros profesionales para poder indicarles en qué aspectos deben mejorar y ampliar sus estudios, pues estamos pendientes de la constante superación en cada una de las áreas que se requieren para la formación integral de nuestros niños. Todo lo anterior, con base en el diagnóstico inicial. Un objetivo es la participación activa de los estudiantes en el proceso: los pioneros son los protagonistas de todo lo que planificamos; ellos deben conocer por qué y para qué los estamos preparando". 
"La educación es un sistema que funciona como una cadena: cuando se rompe un eslabón debe atenderse la dificultad que causó la ruptura, resolverla y continuar con el proceso. Por ello, a través de la escuela se ejerce influencia instructiva en la comunidad, comunidad que está organizada en comités de defensa de la revolución, consejo popular y federación de mujeres cubanas, entre otros".

\section{Las Logopedas son espe- cialistas en atender los tras- tornos del lenguaje y diver- sas dificultades de aprendi- zaje que se presenten a los niños. Son un grupo de diagnóstico y orientación: están al tanto del desarrollo integral del niño.}

\section{¿Qué son las logopedas?}

Las Logopedas son especialistas en atender los trastornos del lenguaje y diversas dificultades de aprendizaje que se presenten a los niños. Son un grupo de diagnóstico y orientación: están al tanto del desarrollo integral del niño. "Nuestros alumnos tienen diferencias en cuanto a rendimiento (bajo, medio y alto), pero ello no conduce a que se les diferencie, pues estamos preparados para tratarlos como iguales y formarlos integralmente". Con respecto a la atención diferencial, una de las logopedas aclara: 'Los maestros de primer ciclo trabajan muy relacionados con el maestro de preescolar, ya que desde ahi se comienza a bacer la caracterización psicopedagógica del niño, mediante pruebas diagnósticas sobre habilidades adquiridas en preescolar (manualidades, lengua, control muscular, matemática y afectividad), que nos dan un nivel de 1 a 5 a alto aprendizaje. Así, el docente recibe al niño o niña en primer grado, y de acuerdo con la caracterización, prepara sus actividades de aprestamiento, encaminadas a resolver las dificultades que se le presenten. Por ejemplo, al niño que tiene un nivel 5 , alto nivel cognoscitivo, se le bacen actividades con mayor exigencia, para que no se sienta desinteresado por sus desempeño. Hago una aclaración: en preescolar no se enseña ni a leer ni a escribir. Aqui, enseñamos primero a leer y luego a escribir, en el primer grado. Al niño se le enseña con mayor rapidez; por eso la caracterización psicopedagógica contribuye, en mucho, a la formación de los estudiantes".

La logopeda continúa ampliando sobre otros aspectos de su trabajo: "I a creatividad y los intereses de los niños se tienen en cuenta de la siguiente manera: en su grado, el maestro busca talentos y determina cuál es el área de mayor interés para el niño talento, entonces aprovecha sus potencialidades para que influy a positivamente en el desarrollo intelectual y creativo del resto del curso, sin producir consecuencias negativas. El contenido que se imparte en el curso se va evaluando sistemáticamente; al concluir se aplica una prueba final para determinara su coberencia con el diagnóstico inicial"

¿Cuál es la función de la auxiliar pedagógica?

La auxiliar pedagógica contribuye a la reafirmación de los conocimientos que los niños han recibido de sus maestros.

Después de que la maestra de grado ha cumplido con su jornada de trabajo, la auxiliar pedagógica reafirma los conocimientos adquiridos por los niños. Aunque la jornada de los niños normalmente concluye al medio día, la auxiliar pedagógica permanece en la escuela durante ocho horas. En las horas de la tarde, según lo ameriten las circunstancias, la maestra de grado acompaña a la auxiliar para trabajar conjuntamente o para revisar el trabajo planeado para el otro día. 
Luego de esta caracterización general de la escuela, cada uno de los visitantes se dirigió a diferentes salones para acercarse un poco más a sus procesos de trabajo interno.

En un salón de preescolar, los pioneritos reciben a los visitantes así: Les voy a bacer una pregunta a ver quién me la responde, ¿Cuál de las vocales es la más importante? Se escuchan diferentes respuestas: la i ,la o, etc. Abora les presentaremos la obra de teatro: ¿Cuál es la más importante?

Fue un corto montaje sobre la necesidad de las vocales, en el que se mostró que en un colectivo todos son importantes y ninguno sobra, pues todos sus miembros son importantes.

En el salón de grado 5D, luego del saludo, ofrecieron estas palabras de recibimiento: " $\mathrm{na}$ cen del fruto las semillas. Nosotros los pioneros somos el semillero de la vida". "Fidel, eres un gran dirigente". Como siempre, concluyen la intervención con una frase del maestro: "Ser cultos para ser libres", José Martí.

En este destacamento, la niña Glenda Garrido es la Jefe y a nombre de éste entrega un recordatorio que dice así: "L Los niños cubanos somos pioneros y tenemos nuestro uniforme $y$ atributos pioneriles, los cuales cuidamos y respetamos. Cada dia le rendimos respeto a nuestra bandera, y, siempre juntos, a José Martí. En nuestras escuelas nos esperan cada dia tareas y conocimientos nuevos, los cuales cumplimos con responsabilidad. Todos asistimos puntuales y diariamente ".

Seguidamente formulan preguntas a los visitantes:

- En su país, zcuántos niños bay en una aula?

- Allá, ¿hay pioneros? ¿Cómo es su uniforme?

- ¿Por qué motivo definen los colores para los uniformes?

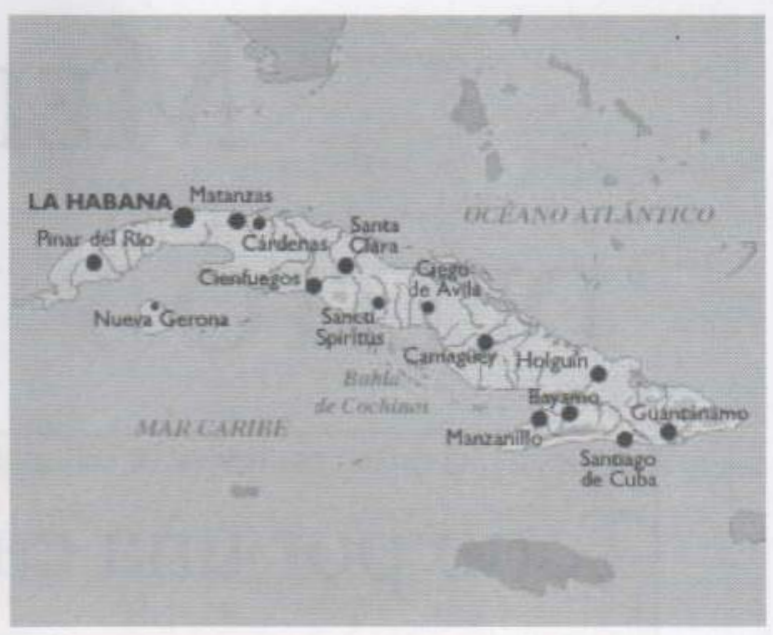

Imagen: Pequeño Larousse Interactivo 2000

¿Qué nombres tienen sus escuelas? ¿Por qué les asignan esos nombres?

Ante las respuestas dadas a cada uno de los interrogantes, los pioneros se asombran, porque en la mayoría de las instituciones públicas colombianas los salones albergan más de 35 estudiantes, mientras que allí solo hay 20 estudiantes por salón. Les extraña que los colores de los uniformes no simbolizan nada especial y que los nombres de las instituciones educativas respondan a intereses que no siempre se relacionan con nuestra independencia.

Al finalizar la mañana todo el personal de la escuela salió a despedir a los visitantes; un pasacalle, con letras grandes, nos recordó que "en la Escuela se ba de aprender el manejo de las fuerzas con que en la vida se ba de luchar", José Martí. Sobre éste fondo, los pioneros ondearon sus pañoletas y, con cantos, palabras de despedida y frases del maestro José Martí, expresaron su contento por poder mostrarnos una de las maneras como se concibe y desarrolla la educación en Cuba. 